
\title{
25 Research Square \\ Identification and Characterization of a Novel Potyvirus Infecting Paris Yunnanensis
}

\section{Pingxiu Lan}

Yunnan Agricultural University

Peng He

Yunnan Agricultural University

Mengji Cao

Southwest University

Guohua Zhou

Yunnan Baiyao Group

Chenrong Li

Yunnan Agriculture University: Yunnan Agricultural University

Guanlin Tan

Yunnan Agricultural University

Xiaojiao Chen

Yunnan Agricultural University

Jie Yang

Yunnan Agricultural University

Taiyun Wei

Fujian Agriculture and Forestry University

Fan Li ( $\nabla$ fanli@ynau.edu.cn )

Yunnan Agricultural University https://orcid.org/0000-0002-4394-2431

\section{Research Article}

Keywords: Paris yunnanensis, open reading frame (ORF), plum pox virus, chilli veinal mottle virus, Paris mottle associated virus (PMaV)

Posted Date: November 8th, 2021

DOI: https://doi.org/10.21203/rs.3.rs-895232/v2

License: (c) (1) This work is licensed under a Creative Commons Attribution 4.0 International License. Read Full License 


\section{Abstract}

The complete genomic sequence of a novel potyvirus from Paris yunnanensis was determined by highthroughput sequencing then confirmed by Sanger sequencing. Its genomic RNA consists 9600 nucleotides (nt) excluding the 3 '-terminal poly (A) tail, containing a typical large open reading frame (ORF) of potyviruses and encoding a putative polyprotein of 3098 amino acids (aa). Pairwise comparison analysis showed the virus shares sequence identity with other members of Potyvirus was $53.0 \%$ to $57.8 \%$ at genome sequence level, and $39.3 \%$ to $51.2 \%$ at polyprotein sequence level. Phylogenetic analysis indicated that the virus was most closely related to the subgroup of plum pox virus and that of chilli veinal mottle virus within the genus Potyvirus. These results suggest that the virus should be considered as a distinct species within the genus Potyvirus and was tentatively named as "Paris mottle associated virus" (PMaV).

\section{Introduction}

Paris yunnanensis (Chonglou in Chinese), previously recognized as a conspecific variety of Parispolyphylla var. yunnanensis, is a perennial herb in the genus Paris of family Melanthiaceae [1]. P. yunnanensis is an important Chinese traditional herb and major component material for at least 49 Chinese patent medicines, such as Yunnan Baiyao Powder and Snake-bite Therapeutics. The plant was naturally growing in the 1400-3200 meter altitude of shady place in Southwest China, but it was gotten to the edge of extinction for long time excessive excavation. Since 1980s, the $P$. yunnanensis plant had been commercially planted for meeting the market demand and protection the plant resource. Its planting area was beyond $10000 \mathrm{hm}^{2}$ with an annual production about 50 thousand tons and profit of 10 billion CNY (ca. 1.6 billion USD) in recent years [1]. However, several viral pathogens, including Paris polyphylla virus $\mathrm{X}$ (PPVX) [2], Paris mosaic necrosis virus (PMNV) [3], pepper mild mottle virus (PMMoV) [4], Paris virus 1 (ParV1) [5], Paris virus 2 (ParV2) [6] and chilli veinal mottle virus [7] had been reported infecting the cultivation plants of $P$. yunnanensis and caused production declining. This paper investigated the viral disease of $P$. yunnanensis in several counties of Yunnan province, determined and characterized the complete genome sequence of a novel potyvirus from the plants with leaf mottle and heavy mottle.

\section{Materials And Methods}

In August 2017, symptoms of foliar mottle and yellowing were observed in a P. yunnanensis commercial plantation of Mangshi, Dehong autonomous prefecture of Yunnan Province (Fig. 1A). Leaves samples from nine disease plants were collected and pooled for total RNA extraction and high-throughput sequencing (HTS). The qualified total RNA was depleted ribosomal RNA and then subjected to HTS RANseq on the Illumina HiSeq X-ten platform with PE150 bp (Vazyme Biotech Co., Ltd, Nanjing, China). The sequence data were analyzed by CLC Genomic Workbench 9.5 (QIAGEN) and a total of 64,278,370 pairedend reads were obtained, with which 105,208 contigs larger than 200 bp were assembly generated by de novo. ORF finding and Blatsx analysis revealed that a large contigs of $9504 \mathrm{nt}$ in length was represented the preliminary genome scaffold of a potyvirus. 
To confirm the presence of the potyvirus in the field plants and amplify its whole genome sequence, Specific primers covering its entire genome sequence were designed according to the $9504 \mathrm{nt}$ contig. All primers have an overlapping region of $\sim 115$ to $151 \mathrm{nt}$ at the ending of the contiguous amplicons (Table S1). Total RNAs from the initial 9 plants sample $(0.1 \mathrm{~g}$ each) were extracted using EasyPure Plant RNA kit (TransGen Biotech, Beijing, China). RT-PCR was performed using a PrimeScript ${ }^{\text {TM }}$ One-step RT-PCR Kit ver. 2 (TaKaRa Biotechnology Co., Ltd., Dalian, China). The 5'-end sequence was obtained using SMARTer ${ }^{\circledR}$ RACE 5'/3' kit (TaKaRa Biotechnology Co. Ltd., Dalian, China), while the 3'-terminus was amplified using a virus-specific forward primer as well as the degenerated primer of viral8 and viral9 designed for the viruses with poly (A) tail [8]. The amplicions expected to the primers designed were purified then cloned into pMD19-T vector [TaKaRa Biotechnology (Dalian) Co. Ltd., Dalian, China], at least three overnight culture clones for each amplicion were selected for sequencing (BGI, Guangzhou, China) and analysis. The genomic sequences were assembled by DNASTAR 7.0 package (DNASTAR Inc., Madison, WI, USA). Pairwise comparisons of nucleotide and polyprotein sequences were performed using the EMBOSS Needle Pairwise Sequence Alignment at https://www.ebi.ac.uk/Tools/psa/emboss_needle/. Multiple alignment was performed using the Clustal Omega Mutiple Sequence Alignment at https://www.ebi.ac.uk/Tools/msa/clustalo/. Nine highly conserved proteolytic cleavage sites in its polyprotein were predicted using multiple alignment of relevant potyviruses polyprotein according to the criteria proposed by Adams et al [9]. Phylogenetic trees were constructed using maximum likelihood (ML) method in the MEGA 7 software [10].

\section{Results}

\section{Results and analysis}

The complete genomic sequence of the virus from mangshi (designed as YMSh-CL isolate) was determined to be 9600 nucleotides (nt) excluding the 3'-terminal poly (A) tail (GenBank accession No. OK073904), flanked by 5' and 3' untranslated regions (UTRs) of $136 \mathrm{nt}$ and $170 \mathrm{nt}$, respectively. The major putative ORF encoding a polyprotein of 3098 amino acid (aa) residues which started at nt 137 and ended at nt 9432. Nine highly conserved proteolytic cleave sites were identical to those of other potyvirus and bioinformatically yielded ten putative mature proteins of P1 (316 aa), HC-Pro (458 aa), P3 (378 aa), 6K1 (51 aa), Cl (636 aa), 6K2 (53 aa), VPg (187 aa), Nla-Pro (243 aa), Nlb (515 aa) and CP (261 aa), respectively (Fig. 1B). The small ORF (PIPO) within the P3 cistron of potyviruses was identified by the presence of ${ }^{3007}$ GGAAAAA 3014 encoding a protein of 73 aa residues. Most conserved motifs of potyviruses [11], such as ${ }^{6} \mathrm{I}-\mathrm{T}-\mathrm{F}-\mathrm{G}^{9}$ and ${ }^{228} \mathrm{H}-\mathrm{X}_{12}-\mathrm{D}-\mathrm{X}_{29}-\mathrm{S}-\mathrm{G}-\mathrm{X}_{18}-\mathrm{R}-\mathrm{G}^{292}$ associate with protease activity in $\mathrm{P} 1$, the putative zinc finger metal-binding motif of ${ }^{27} \mathrm{C}-\mathrm{X}_{8}-\mathrm{C}-\mathrm{X}_{18}-\mathrm{C}-\mathrm{X}_{2}-\mathrm{C}^{58}$ related to aphid transmission, and ${ }^{344} \mathrm{C}-\mathrm{X}_{72}-\mathrm{H}^{417}$ for protease activity in HC-Pro ${ }^{106} \mathrm{~V}-\mathrm{L}-\mathrm{M}-\mathrm{V}-\mathrm{E}-\mathrm{P}-\mathrm{T}-\mathrm{R}-\mathrm{P}-\mathrm{L}{ }^{115}{ }^{175}{ }^{175} \mathrm{D}-\mathrm{E}-\mathrm{C}-\mathrm{H}^{178}$, ${ }^{202}$ K-V-S-A-T-P-P ${ }^{208},{ }^{253}$ L-V-Y-V $256,{ }^{304}$ V-A-T-N-II-E-N-G-V-T-L ${ }^{315}$ and ${ }^{348}$ G-E-R-I-Q-R-L-G-R-V-G-R ${ }^{359}$ related to the potential helicase activity in $\mathrm{Cl}^{46} \mathrm{H}-\mathrm{X}_{34}-\mathrm{D}-\mathrm{X}_{67}-\mathrm{G}-\mathrm{X}-\mathrm{C}-\mathrm{G}-\mathrm{X}_{14}-\mathrm{H}^{167}$ with proteolytic activity in Nla-Pro, ${ }^{188}$ F-T-A-A-P-I-D ${ }^{194},{ }^{202}$ C-V-D-D-F-N ${ }^{207},{ }^{244}$ F-D-A-D-G-S ${ }^{249},{ }^{306}$ G-N-N-S-G-Q-P-S-T-V-V-D-N-S-L-M-V ${ }^{322}$ and 
${ }^{350} \mathrm{G}-\mathrm{D}-\mathrm{D}^{352}$ for

RNA-dependant polymerase in NIb were all

identified in the virus. Besides, the highly conserve motif of K-I-T-C in HC-Pro involved in aphid transmission, was taken place by ${ }^{52} \mathrm{R}-\mathrm{-}-\mathrm{T}-\mathrm{C}^{55}$ in the virus, while two other motifs of ${ }^{310} \mathrm{P}-\mathrm{T}-\mathrm{K}^{312}$ in HC-Pro and ${ }^{7} \mathrm{D}-\mathrm{A}-\mathrm{G}^{9}$ in $\mathrm{CP}$ with the similar function, both present in its corresponding location.

The sequences of the virus were pairwise compared with other members of genus Potyvirus available in the GenBank Database, the result showed the virus sharing sequence identity with other members of Potyvirus was 53.0\% (onion yellow dwarf virus, OYDV, Accession number NC_005029) to 57.8\% (NYSV, Accession number NC_011541) at nt sequence level, and 39.3\% (OYDV, NC_005029) to 51.2\% (plum pox virus, PPV, NC_001445) at deduce aa sequence level. A maximum-likelihood tree was conducted using the deduced polyprotein sequence and selected members of the genus Potyvirus. The virus was clustered as a single clade between the subgroup of plum pox virus group and that of chilli veinal mottle virus (Fig. 2). These results indicated that the virus should be a novel species of genus Potyvirus and was tentatively named as "Paris mottle associated virus" (PMaV).

Mechanical inoculation proved that Nicotiana benthamiana, N. tobacum, N. glutinosa, N. rustica, N. tabacum var. Xanthi nc, Capsicum annuum, Solanum lycopersicum and Vigna unguiculata are not host plants of PMaV. 33 out of 132 samples from 4 counties of Mangshi, Tengchong, Lijiang, Lushui from Yunnan proved infecting with $\mathrm{PaMoV}$ indicting a relatively wide areas of the virus. However, more biological characteristics should be examined in the future for the vector transmission still unknown.

\section{Declarations}

Acknowledgments: This study was funded by the National Science Foundation of China (31660509) and the Yunnan Academician Expert Workstation (202005AF150040).

\section{Compliance with ethical standards:}

Conflict of interest: The author declares no competing interests.

Ethical approval: This article does not contain any studies with human participants or animals performed by any of the authors.

\section{References}

1. Ji YH. (2021). A Monograph of Paris (Melanthiaceae) [M]. Science Press (Beijing) and Springer Press (Singapore): 69-81.

2. Dong JH, Ding M, Fang Q, Luo YQ, Zhang ZK, Li Z, Yang B, Li XM (2007). Molecular identification of a Potexvirus isolate infecting Paris polyphylla var. yunnanensis and analysis of 3'terminal sequence. Acta Phytopathol Sin 37 (3): 237-241 
3. Lan PX, Zhao JR, Zhou YL, Li YY, Shen DC, Liao QC, Li RH, Li Fan (2018). Complete genome sequence of Paris mosaic necrosis virus, a distinct member of the genus Potyvirus. Arch Virol 163(3):787-790

4. Wen GS, Yang LY, Anane R., Chen Z., Yang Y., Chen L., Sun Y., Zhao M (2019). First report of pepper mild mottle virus in Paris polyphylla var. yunnanensis in China. Plant Dis 103 (12):3289

5. Chen L, Anane RF., Wang Z, Yang L, Chen ZL, Wen GS, Zhao MF (2020). Whole-genome sequence analysis of paris virus 1: a novel member of the genus Potyvirus infecting Paris polyphylla var. yunnanensis. Arch Virol 165(4):985-988

6. Chen L, Anane RF., Wang Z, Chen ZL, Gao L, Wen GS, Zhao MF (2021) Characterization of a novel Tombusviridae species isolated from Paris polyphylla var. yunnanensis. Arch Virol https://doi.org/10.1007/s00705-021-05191-y

7. Yang J, Ma QZ, Meng Y, Huang D, Li CR, He P, Li F, Lan PX, Tan GL (2021) First report and partial genomic sequence analysis of ChiVMV in Paris yunnanensis. Acta Phytopathol Sin https://doi.org/doi:10.13926/j.cnki.apps.000573

8. Lan PX, He P, Zhang YK, Zhang S, Zhang ZB, Chen XJ, Tan ST, Luo HM, Cao MJ证i Fan (2019) Molecular characterization of a novel potyvirus infecting noni. Arch Virol 164(12):3099-3102.

9. Adams MJ, Antoniw JF, Beaudoin F (2005). Overview and analysis of the polyprotein cleavage sites in the family Potyviridae. Mol Plant Pathol 6(4):471-487

10. Kumar S, Stecher G, Tamura K (2016). MEGA 7 : Molecular evolutionary genetics analysis version 7.0 for bigger datasets. Mol Biol Evol 33(7):1870-1874.

11. Worrall EA, Hayward AC, Fletcher SJ, Mitter N. (2019). Molecular characterization and analysis of conserved potyviral motifs in bean common mosaic virus (BCMV) for RNAi-mediated protection. Arch Virol 164(1):181-194

\section{Figures}


A

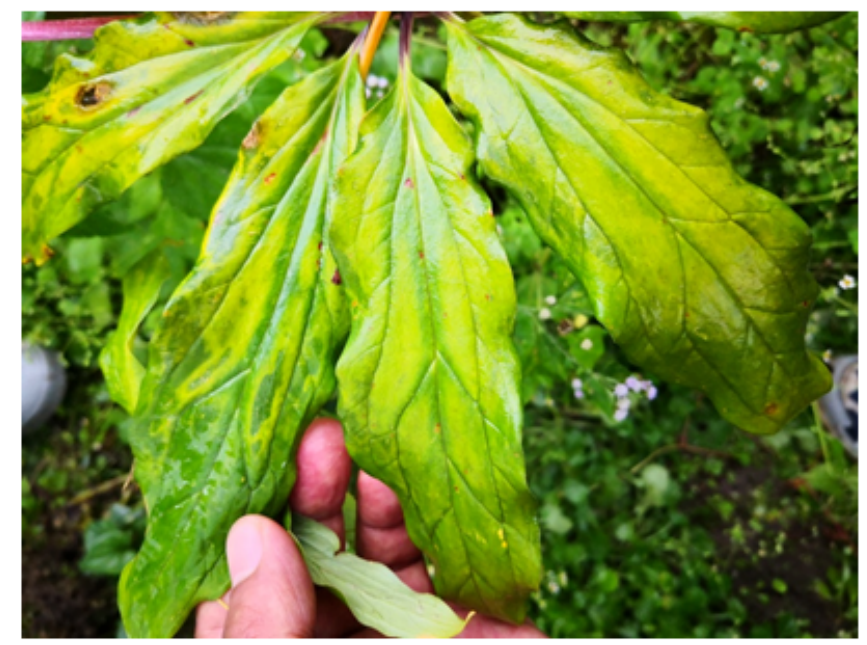

B

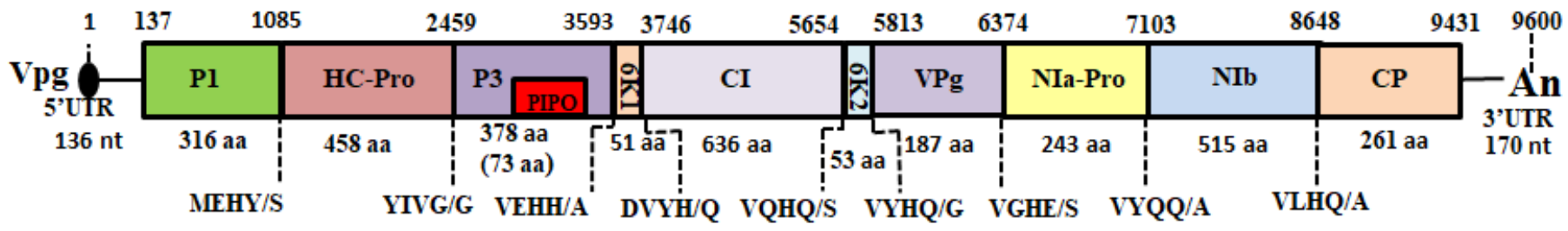

\section{Figure 1}

Symptoms and genome organization of Paris mottle associated virus (PMaV). (A) Symptoms induced by PMaV. (B) Schematic representation the genome organization of PMaV. The 5'- and 3'-untranslated regions (UTR) are represented by a solid lines, and the open reading frame (ORF) is depicted by an open box with solid line. The putative protein PIPO is indicated within P3 protein by a small box in red. The putative proteolytic cleavage sites in the polyprotein and the length in amino acids of each protein is indicated below the genome, whereas the numbers above the genome indicate the start for each region. 


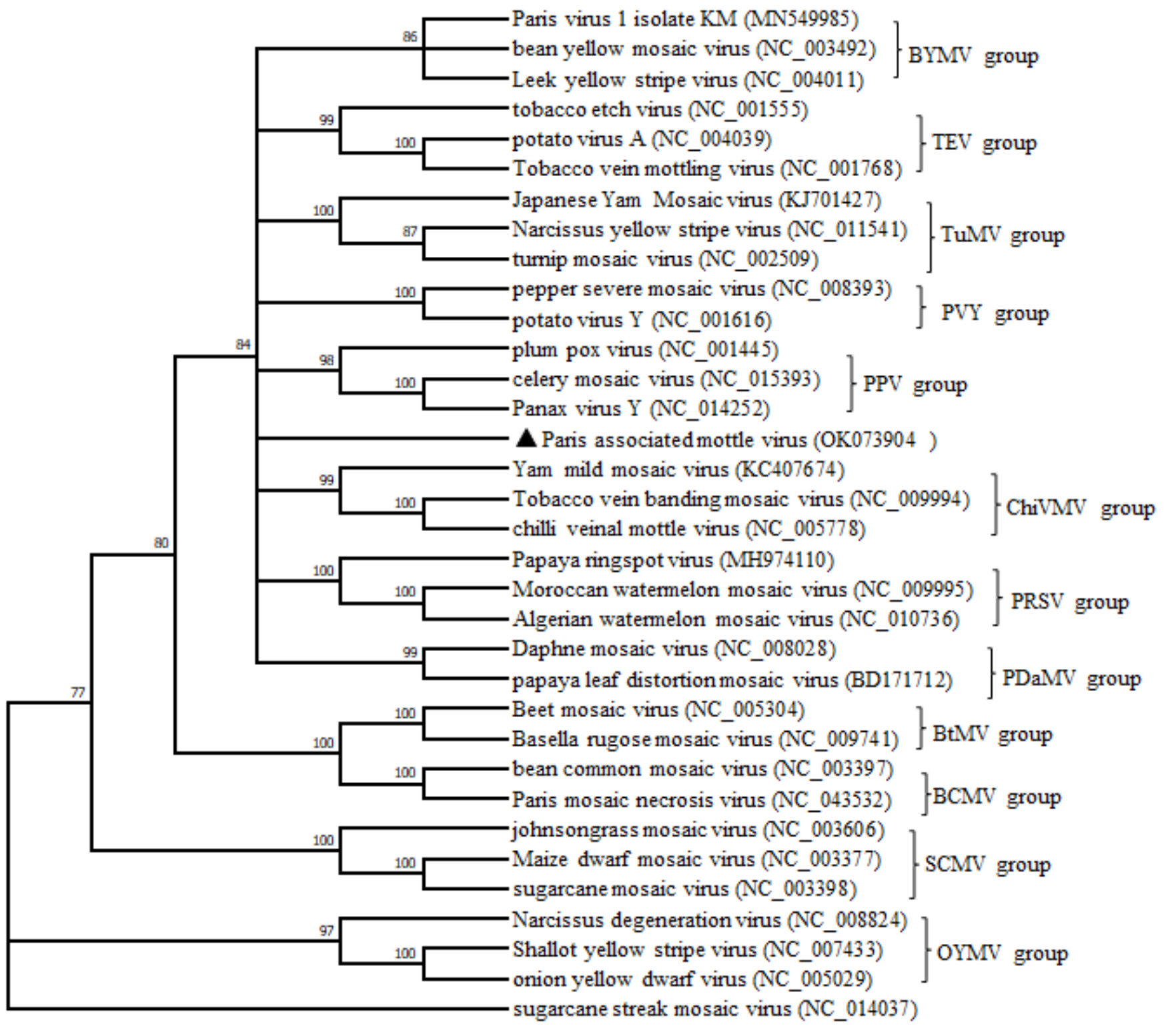

Figure 2

Maximum-likelihood tree based on the deduced polyprotein of PMaV as well as those of the representative members of genus Potyvirus. Bootstrap analysis was applied using 1000 bootstrap replicates. Sugarcane streak mosaic virus, a member of genus Poacevirus, was used as an outgroup. Solid triangle indicated the PMaV-Mshi isolate characterized in this study.

\section{Supplementary Files}

This is a list of supplementary files associated with this preprint. Click to download.

- Summplmenttable.docx 